\title{
Invention on Correlation between the chemical composition of the surface sediment and water in the mangrove forest of the Sundarbans, Bangladesh, and the regeneration, growth and dieback of the forest trees and people health
}

\author{
Awal, Mohd Abdul \\ Founder \& Chief Advisor, Health \& Pollution Research Farm, 23-09-37 Avenue, Apt, No: 1, Long Island City, New York, USA.
}

\section{Email address:}

abdul_awal2004@yahoo.com

\section{To cite this article:}

Awal, Mohd Abdul. Invention on Correlation between the Chemical Composition of the Surface Sediment and Water in the Mangrove Forest of the Sundarbans, Bangladesh, and the Regeneration, Growth and Dieback of the Forest Trees and People Health. Science Innovation. Vol. 2, No. 2, 2014, pp. 11-21. doi: 10.11648/j.si.20140202.11

\begin{abstract}
Sundarbans in Bangladesh has been facing tremendous environmental pollution problems, including that of dieback (top-dying) of the main tree species (Heritiera fomes), and also various health hazards among the surrounding people in Sundarbans, Bangladesh, which is affecting millions of trees and people in Sundarbans areas (Awal, M.A. 2007). The cause of this dieback and health hazard is unknown. The present work has investigated one of the possible factors that might be causing this top-dying, namely the concentrations of various chemical elements present in the sediments, particularly heavy metals, though other chemical parameters such as the $\mathrm{pH}$, salinity, moisture content of the sediment and nutrient status were also assessed. Tree height and trunk diameter were determined as indications of tree growth, counts of seedlings and saplings were made to assess regeneration success, and the intensity of top-dying within the sampled plots was recorded on a rank scale. In order to establish the views of local people about the incidence and causes of top-dying and health hazard, a questionnaire was prepared for asking peoples either individually or in groups. This survey was done among people living or working in the 17 Sub-Districts of Sundarbans, making a distinction between those living within and outside of Sundarbans. So, this survey was performed to receive their indigenous response and knowledge towards top dying, and its present conditions, and their ideas about what leads to top-dying, as well as questions about tree regeneration and human health in Sundarbans. As well as seeking evidence about the health status of the Sundarbans, the questionnaire attempted to assess whether there were increasing health issues for the local people resident in the area of Sundarbans. According to the people thought that several human health problems are present among the neighbouring peoples of Sundarbans areas. These included particularly skin irritation, black spots on organs of their bodies such as hands and on arms, as well as spots on their faces, dysentry and diarrhoea, and cholera problems. They thought that excessive abnormal concentrations of metals, with Arsenic being particularly mentioned and also excessive salinity, were responsible for these diseases.
\end{abstract}

Keywords: Causal Factors, Heavy Metals, Top-Dying Disease, People Health Problems, Environmental Factors

\section{Introduction}

The Sundarbans is the largest single mangrove forest in the world, occupying about $6,000 \mathrm{~km}^{2}$ in Bangladesh and the rest in India (Iftekhar \& Islam, 2004). The Sundarbans supports a diverse fauna and flora (e.g. Prain, 1903; Siddiqi et al., 1993, Iftekhar, 2006), approximately millions people of Bangladesh, Nepal, Burma, and India depend on it directly for their livelihood (Awal, M.A. 2007; Iftekhar \&
Islam, 2004), and also it provides a critical natural habitat which helps protect the low lying country and its population from natural catastrophes such as cyclones such as Sidr, Resmi, Ayla etc. (e.g. Blasco et al., 1992; Iftekhar, 2008). Actually, mangroves in Asia including Bangladesh, India, and East Africa previously contained a much fuller range of species (Seidensticker, and Hai, 1983; Khan, 1997).The Sundarbans mangrove forest was declared a reserve in 1876 due to its biodiversity and subsequently 
declared a world heritage site in 1997(IUCN,1997; Government of Bangladesh,1997). In the Southeast Asian region, species diversity of mangroves was previously much higher, where approximately two-thirds of all species and $70 \%$ of the major vegetation types with $15 \%$ of terrestrial species in the Bangladesh-India-Malayan realm have already been destroyed (Ellison, 1998, 2000).

\subsection{Overview of Environmental Factors for Causes of Heavy Metal Contamination}

Mangroves in general have been negatively affected by both coastal development and environmental pollution problems (Awal, M.A. 2007; Peters \& Darling, 1985), in particular pollution from oil spillages, and in some areas the discharge of toxic wastes (UN-ESCAP 1988). Deep mud coastal habitats may take 20 years or more to recover from the toxic effects of such oil spills (Phillips \& somebody, 1994). Environmental pollution is also carried into the Sundarbans by Heavy metals, the rivers, particularly the un-treated pollutants and wastes of Ganges, which carries untreated municipal wastes, industrial effluents and agro-chemical residues (Hossain, 2001; Sarkar et al., 2003). In the Sundarbans in Bangladesh a large number of industries are discharging untreated effluents directly into the river water at Khulna, which will contaminate soil further downstream in the Sundarbans forest floor (UN-ESCAP, 1987; Wahid et al., 2007). The polluting industries are Khulna Newsprint Mill, hardboard mills, some match factories, Mongla port areas, fish processing units, Goalpara power station, some jute mills and Khulna shipyard. Khulna Newsprint Mill alone continuously discharges nearly $4500 \mathrm{~m}^{3} \mathrm{ha}^{-1}$ of waste water containing high levels of suspended solids (300-500 $\mathrm{mg}^{-1}$ ) environmental pollutants, and sulphur compounds (Awal, M.A. 2007; UN-ESCAP, 1987). Moreover, re-suspension of dredging material for port development is a potential threat to the Sundarbans due to long lasting toxicological effects from chemical or heavy metal pollution. Although information regarding the quantity of pollutants and the extent of damage to soil and water quality and natural resources is very meagre (Awal, M.A. 2007; Hossain, 2001), recent evidence (Awal et al., 2009) indicates that the Sundarbans has indeed been subject to pollution problems, with elevated concentrations of some heavy metal contaminants found(Awal, M.A. 2007)..

The historically dominant tree species in the Sundarbans is Heritiera fomes (local name 'Sundri') (Karim, 1994; Ellison et al., 2000), which occurs extensively in the Bangladesh part of the Ganges delta because of the lower salinity there compared to the western part (Blasco et al., 1996). Besides other threats to the integrity and survival of the Sundarbans forest system, trees of Heritiera fomes have been reported to be suffering from 'top-dying', a form of dieback (Chaffey et al., 1985; Iftekhar \& Islam, 2004). This condition starts with a decline or death of foliage and twigs in the upper part of the tree, and gradually the symptoms extend downward. This gives a stag-headed condition to the affected trees (Gibson, 1975), but ultimately the condition leads to the death of the tree. The incidence of such topdying is thought to have increased in more recent years (e.g. Chaffey et al., 1985). An inventory by Chaffey et al. (1985) revealed that there were about 45.2 million trees suffering from top-dying in the Sundarbans, of which 20 million had more than $50 \%$ of their crown affected. This contributes to changes in vegetation and consequent ecosystem degradation (Iftekhar \& Islam, 2004).

\subsection{Proof and Dis-Proof of Previous Hypotheses Till Now}

Although various hypotheses have been put forward to explain this top-dying (e.g. Hartung et al., 1998), the cause is not clear still now. Amongst other possible explanations is increased contamination of the sediment by heavy metals, as discussed above, which could be having a direct or indirect effect on the health of the trees and on the health of the people who are living in the Sundarbans. Average values from the chemical analyses by ICP-MS of the elemental composition of the mangrove sediments have been presented in an earlier publication (Awal et al., 2009). They showed a tendency to elevated concentrations for some trace elements, and a marked difference in certain elements between the different compartments of the Sundarbans. This paper reports a study into the relationship between elemental concentrations in the mangrove sediments or water and the regeneration, growth and relative incidence of top-dying of the trees, in order to assess whether variation in such concentrations is linked to top-dying status.

\subsection{Location}

The mangrove zone of Bangladesh is about $710 \mathrm{~km}$ long including several tiny islands (Rahman, et al., 2003). In the present day the Indo-Malayan mangroves are confined to Sundarban reserved forests, mainly in Bangladesh. According to Miller et al. $(1985,1981)$, this forest had been affected by human settlement and agricultural activities during and under both the Bengal Sultanate (1204-1575) and the Mughal Empire (1575-1765). At the arrival of British rule in 1765, the Sundarbans forests were double their present size and significant exhaustion of the growing stock led to dwindling by $40 \%-45 \%$ between 1959 and 1983 (Chaffey et al., 1985). 


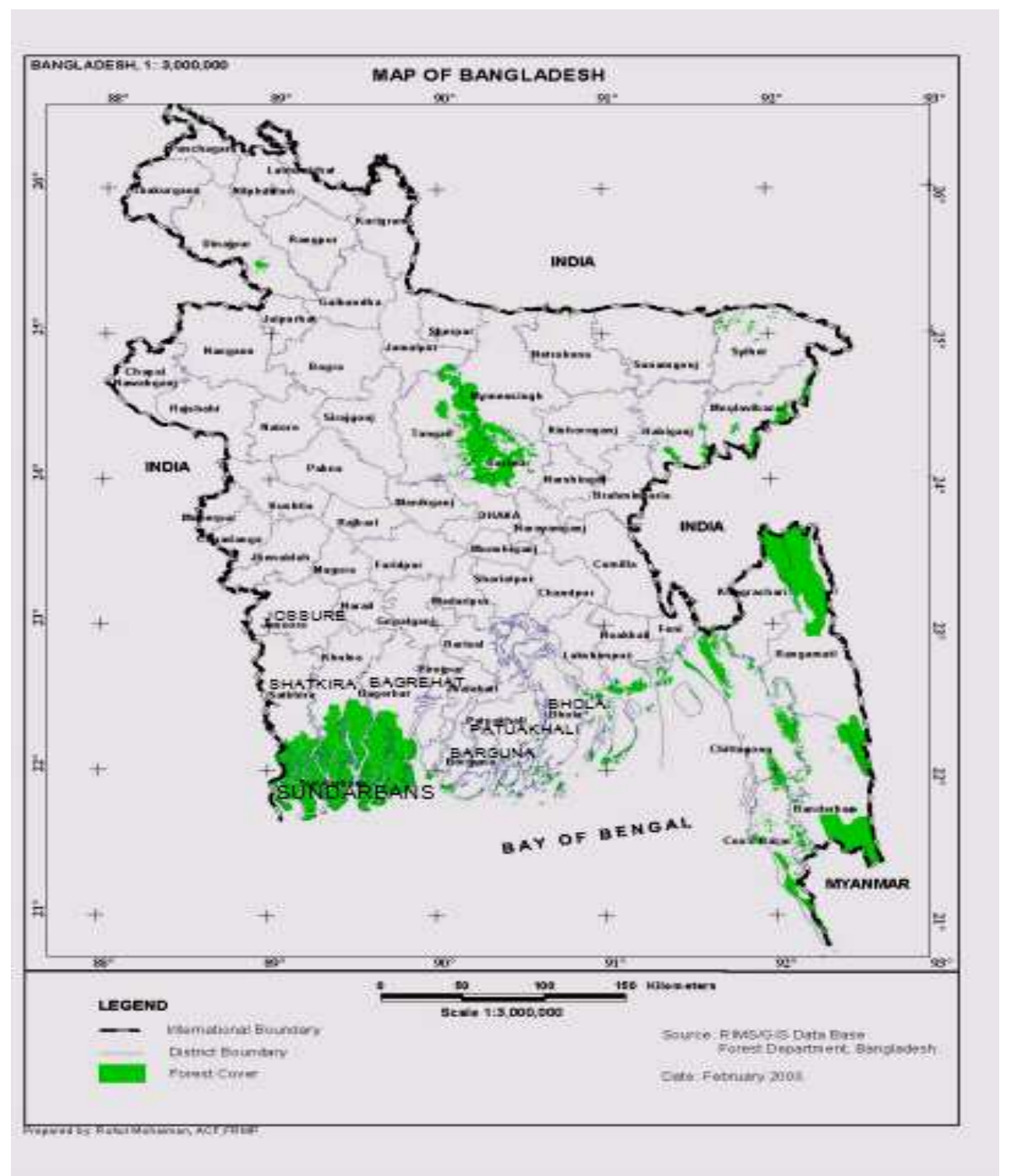

Figure 1.1. Map showing the administrative districts of Bangladesh, including the location of the Sundarbans (the shaded area in the south-west of the country).

\section{Methodology}

Nine plots were selected for sampling, choosing areas to reflect different intensities of top-dying. Sixty-three(63) sediment samples were tested for the various parameters, including $\mathrm{x}$ elemental concentrations being determined by ICP-MS. The relationships between top-dying and chemical or growth parameters were tested using correlation coefficients, the variations between plots were tested using analyses of variance and differences in seedling and sapling numbers using chi-square statistics. Results of seedling and sapling regeneration showed a marked reduction in numbers in areas with greater concentrations of several chemical parameters. However, adult tree growth was generally not correlated with the chemical parameters. Also, most of the individual elements and parameters studied had no significant correlation with the average intensity of top-dying of Heritiera fomes. However, exchangeable $\mathrm{K}$, sediment moisture content and sediment $\mathrm{pH}$ were significantly related and $\mathrm{Sn}, \mathrm{Pb}, \mathrm{Zn}$ and $\mathrm{Ni}$ were also close to significance. These results show that the chemical composition of the soil appeared to be an important factor related to tree regeneration, though not to adult tree size, and in some cases to be related to the top-dying of Heritiera fomes in Sundarbans. It is suggested that the latter effect is due to a weakening of the vigour of the trees, allowing other factors such as pathogenic agents to attack the plants.

\subsection{Field Sampling Methods}

Fieldwork was performed between October 2003 and March 2004. Sampling was from the area of the Sundarbans near Chandpai, which is the area most accessible to people and also potentially the one that is most polluted. Three areas (termed 'compartments') from this region were selected (numbers 26, 28 and 31) because they were believed to represent a range of severity of top-dying disease as well as 
of human activities, as outlined in Awal et al. (2009). Within each of the three compartments, sampling of vegetation, mangrove sediment and water took place within three $20 \mathrm{~m} \mathrm{x}$ $20 \mathrm{~m}$ plots, chosen to reflect a range of top-dying intensities (high, medium and low for that area). The sampling was conducted in a randomised block design, in that a plot was sited within a particular top-dying intensity block, but the precise location of that plot was randomised so as not to bias the detailed data collection. Therefore a total of nine plots was sampled. It should be noted that the material making up the mangrove sediments will include marine, coastal and freshwater deltaic sediments as well as biological material such as tree litter-fall. The relative importance of these sources will depend to a great extent on the patterns of river discharge (Dyer, 1986) and the extent of tidal inundation, and will also therefore vary spatially throughout the Sundarbans.

From each of the nine plots, one water sample was collected in a plastic bottle from a nearby river, creek or channel. Also, seven sediment samples were collected per plot; one from the centre of the plot, four (one each) from all the corners, and two from the middle sides of the plot. Therefore a total of 63 sediment samples was taken. These mangrove sediment samples were collected from $0-30 \mathrm{~cm}$ depth by using a stainless steel spatula and steel cylinder $(d=5.25 \mathrm{~cm})$, and all samples were kept in sealed plastic bags until sample preparation took place. Samples were preserved in portable coolers until arrival at the laboratory at Dhaka University for initial chemical analysis and air drying. This field sampling method followed the W.H.O, U.K, and E.P.A systems of standard laboratory and field sampling principles, rules and regulations. The dried samples were later transported to Bradford, U.K., for chemical analysis by ICP-MS.

Within each of the nine $20 \mathrm{~m} \times 20 \mathrm{~m}$ plots, each adult tree of all species was assessed for three parameters. The diameter at $1 \mathrm{~m}$ height was recorded (in $\mathrm{cm}$ ) by using a measuring tape or slide callipers, depending on girth. The tree height to the top of the crown was determined mainly by ocular estimation, but some heights were checked by using clinometers at a set distance of $20 \mathrm{~m}$ to test the accuracy of such ocular estimations. Thirdly, the status of the tree in respect of the amount of top-dying was assessed by using a four point qualitative scale of intensity, namely; not affected, mildly affected, moderately affected or highly affected by top-dying. This was later expressed as a semi-quantitative or rank scale and used as an index of top-dying intensity in that plot. After assessing the adult trees, the total number of seedlings (individuals of the tree species $<1 \mathrm{~m}$ tall), and saplings (young trees $>1 \mathrm{~m}$ tall with a diameter of trunk of $<$ $10 \mathrm{~cm}$ ), of all species were counted within the plots. Care was taken to ensure that trees, saplings and seedlings were not counted more than once or missed in the recording process by marking them, using different colours for adult and regenerating trees.

\subsection{Laboratory Analyses}

Initial chemical and physical properties of the mangrove sediment samples and the water were determined in Dhaka
University. These were the electro-conductivity for the determination of sediment and water cation exchange capacity; the $\mathrm{pH}$ of both sediment and water; the percentage moisture content of the sediments; soil particle analysis determined by a Plunger Hydrometer; the concentrations of $\mathrm{S}$ (name of method?), soluble $\mathrm{N}$ (digestion method), and total $\mathrm{N}$ (Kjeldahl method. All remaining elemental concentrations were determined using Inductively Coupled Plasma - Mass Spectrometry (ICP-MS) at Bradford University.

\subsubsection{Electro-Conductivity}

Fifty $\mathrm{ml}$ of distilled water was added to (how much of?) the sediment, and the mixture shaken mechanically and then stirred 5-7 times to ensure thorough mixing. The sediment suspension was left overnight for it to reach its stable suspension position phase. Finally water EC was recorded by using an EC meter.

\subsection{2. $\mathrm{pH}$}

The $\mathrm{pH}$ of the sediment samples was measured by adding $50 \mathrm{ml}$ of distilled water; $20 \mathrm{~g}$ of sedmen was weighed using an analytical balance and placed into a graduated glass beaker, and then $50 \mathrm{ml}$ of distilled water was added to the soil to the sediment, then shaken and stirred 5-7 times to ensure thorough mixing. The mixture was left overnight for it to reach its stable suspension position phase before recording the $\mathrm{pH}$ using a $\mathrm{pH}$ meter. For the $\mathrm{pH}$ of the water samples, $50 \mathrm{ml}$ each of water sample and distilled water were taken, stirring was done in the same way as for the sediment $\mathrm{pH}$ measurement, and the sample solution left overnight before filtering using a Whatman No. 42 filter paper and then recording the $\mathrm{pH}$ as above.

\subsection{Particle Size Analysis}

Each sediment sample was air dried, ground to a powder, sieved, then reacted with hydrogen peroxide solution (H2O2), according to the procedure described in Black et al. (1965). In the hydrometer, the blank reading was taken after 40 seconds, and the second reading after two hours, maintaining the temperature at $29 \mathrm{oC}$; and these values were used to calculate the particle size (Black et al., 1965).

\subsubsection{Percentage Moisture Content of the Sediment}

Approximately $50 \mathrm{~g}$ of sediment was passed through a 2 $\mathrm{ml}$ sieve. The sieved material was then weighed and heated to $105^{\circ} \mathrm{C}$ for 24 hours to dry it completely. The dry sediment was then reweighed and the difference in weights gave the weight of moisture. This amount of moisture was expressed as a percentage of the original wet sediment weight.

\subsubsection{Elemental Concentrations by ICP-MS}

Initial sample preparation was performed at Dhaka University. Adhering materials were removed with forceps, and all sample materials were dried at ambient temperature and were disaggregated to pass a laboratory test sieve using a brush. Soil samples were ground by an acid proof porcelain mortar pestle using a porcelain hammer. After 
making the soil into powder, samples were kept in plastic bags until later analysis.

Subsequent analyses of the dried sediment samples were performed at Bradford University. In all steps of soil sample preparation and analysis, care was taken to avoid contamination. All items of equipment were first washed by hot tap water, soapy water, cold water, then by deionised water or distilled water and finally with acid leached in deionised water. For drying, all items were kept for 12 hours in an oven, then they were washed again by the same procedure before storing, to be washed again immediately prior to starting a new analysis. Instruments were cleaned with appropriate blanks before beginning every experiment.

The 63 samples, together with two reference materials (namely peach leaf, 1547 NIST, and estuarine sediment, 1646 NBS) and blanks as controls were prepared by adding $4 \mathrm{ml}$ of concentrated $1 \mathrm{M} \mathrm{HNO} 3$ solution to $0.2 \mathrm{~g}$ of the sample and pre-digested until the reaction of volatile or easily oxidised materials had subsided. Fresh blank samples were made for each separate set of acid digestions. Soil samples were digested by a Microwave Digestion System (MDS). All samples and solutions of material were kept in a cool room (at approximately 5oC) until they were used for analysis. The samples were then sealed in Advanced Composite Vessels with a rupture membrane and pressure control cover in each, and heated in a microwave oven. The samples were heated slowly up to $103 \mathrm{oC}$, maintaining 175 psi pressure for 12 minutes. The resultant digest was cooled and collected by washing seven times with double-distilled water, filtered, then transferred to a volumetric flask and diluted to make $250 \mathrm{ml}$ volume.

The samples were then analysed for 32 elements: Al, As, B, $\mathrm{Ba}, \mathrm{Bi}, \mathrm{Ca}, \mathrm{Cd}, \mathrm{Co}, \mathrm{Cr}, \mathrm{Cu}, \mathrm{Fe}, \mathrm{Hg}, \mathrm{In}, \mathrm{K}, \mathrm{Mg}, \mathrm{Mo}, \mathrm{Mn}, \mathrm{Na}$, $\mathrm{Ni}, \mathrm{P}, \mathrm{Pb}, \mathrm{Rb}, \mathrm{Sb}, \mathrm{Sc}, \mathrm{Se}, \mathrm{Si}, \mathrm{Sn}, \mathrm{Sr}, \mathrm{Ti}, \mathrm{V}, \mathrm{Y}, \mathrm{Zn}$, using ICP-MS. Calibration standards were required for checking the detector response, and these were prepared with known quantities of the elements at five concentrations $(1,10,100,200$ and 1000 $\mathrm{ppb}$ ) to cover the range of concentrations likely to be found for each element. The calibration standards are typically prepared using 2\% HNO3, but early trials suggested that there might be retention and cross-contamination of $\mathrm{Hg}$ within the equipment using this acid, and therefore $200 \mathrm{ppb}$ gold-wash solution was used instead which improved instrumental response (details in Awal, 2007).

\subsection{Statistical Analysis}

Data on the severity of top-dying for each tree in a plot, which had been recorded as 'not affected', 'mildly affected', 'moderately affected', and 'highly affected', were converted into a four-point scale (0-3), so that they could be summed and an average (median) could be determined for each plot, thus producing an average index score per plot based on ranked data.

Comparisons of the strength of relationship between two variables were assessed by correlation: the Pearson's product-moment correlation coefficient where both variables were fully quantitative, or the Spearman's rank correlation coefficient where the top-dying index was one of the variables. In the case of the Spearman's coefficient, the probability of the outcome was determined by using the approximation to a t-statistic appropriate to these tests (Sokal and Rohlf, 1981). The Spearman's correlation was used here because the top-dying data are based on an index, and probably not meeting all the assumptions of truly parametric data, although since the elemental concentrations are fully quantitative data, using this statistic will result in some information loss.

Data on frequencies of seedlings or saplings in each of the plots and compartments were tested by $\chi^{2}$ contingency table analyses to determine whether the amount of topdying was associated with location. A similar consideration of the different compartments as comprising one factor, and the plot type as a second, was used to test the pattern of elemental concentrations and other variables by a twofactor analysis of variance test with replication. This allows an assessment of the significance, not only of the two factors separately but also of the interaction between the two factors (Zar, 1984). It should be noted that the plot type was not a strictly controlled factor, since the three categories of top-dying intensity were relative to each other within any one compartment and might not have been exactly equivalent between the three categories in different compartments; interpretation of the results from these test therefore needs to bear this in mind. MINITAB version 14 Statistical Software has been used for all data analysis.

\section{Results and Discussion}

\subsection{Comparisons between Plots and Compartments}

The seedling and sapling data for all species (given in Tables 1 and 2 respectively) were analysed by chi-square to test whether the frequencies of the regenerating trees varied in relation to their location, and hence likely intensity of top-dying. The result for seedlings was that $\sum \chi^{2}$ gave a value of 345.28 which was very highly significant $(\mathrm{p}<0.001$, $\mathrm{df}=4)$, while the value of $\sum \chi^{2}$ for saplings was 145.94 and was also highly significant $(\mathrm{p}<0.001, \mathrm{df}=4)$. Clearly, both sets of data for regenerating trees were highly influenced by location, with clear evidence of a reduction in abundance in sites which had been selected as showing high incidences of top dying, with least regeneration in Compartment 31 Plot 1 and, particularly with the sapling data, with the greatest numbers of regenerating saplings in Compartment 26 Plot 3 . That regeneration of seedlings and saplings varied with plots and compartments is consistent with a pronounced effect of top-dying affecting even the youngest individuals (rather than only the older individuals, as reported by [ref needed]). However, the variations in regeneration could be linked to other factors which vary spatially too, such as $\mathrm{pH}$ or nitrogen levels (Matilal et al., 1998); salinity (Ellison et al., 2000; Iftekhar \& Saenger, 2008); heavy metal concentrations (Awal et al., 2009); zonation influences (Blasco et al., 1996); or possibly even 
being suppressed by an alien climbing species Derris trifoliate which inhibits normal growth (Biswas et al., 2007). Thus a significant pattern of regeneration difference was observed, but the cause might not directly be due to top-dying.

Table 1. Frequencies of seedlings in the various compartments and plots of different intensities of top-dying (N.B. for each compartment, high intensity of top-dying $=$ plot 1, medium $=$ plot 2 and low intensity $=$ plot 3$)$.

\begin{tabular}{ccccc}
\hline $\begin{array}{c}\text { Top-dying } \\
\text { intensity }\end{array}$ & $\mathbf{2 6}$ & $\mathbf{2 8}$ & $\mathbf{3 1}$ & Total \\
\hline High & 1261 & 1440 & 625 & 3326 \\
Medium & 1326 & 1501 & 1430 & 4257 \\
Low & 1455 & 1575 & 1830 & 4860 \\
Total & 4042 & 4516 & 3885 & 12443 \\
\hline
\end{tabular}

Table 2. Frequencies of saplings in the various compartments and plots of different intensities of top-dying (plots are as in Table 1).

\begin{tabular}{lllll}
\hline Top-dying & \multicolumn{2}{l}{ Compartment } & & \multirow{2}{*}{ Total } \\
intensity & $\mathbf{2 6}$ & $\mathbf{2 8}$ & $\mathbf{3 1}$ & \\
\hline High & 282 & 228 & 167 & 677 \\
Medium & 266 & 172 & 396 & 834 \\
Low & 566 & 215 & 343 & 1124 \\
Total & 1114 & 615 & 906 & 2635 \\
\hline
\end{tabular}

Data on the number of adult trees of all species, the average and maximum tree height, the average tree diameter, tree density and average (median) top-dying score are included in Table 3.3. It should be noted that, although all tree species (a total of six) are included in these data, since the species Heritiera fomes accounted for $84 \%$ of all individuals, essentially the values relate to the growth response of this species rather than any of the others.

Table 3. Parameters of the vegetation structure and average top-dying intensity from the nine sampled sites.

\begin{tabular}{|c|c|c|c|c|c|c|c|}
\hline $\begin{array}{l}\text { Compart-ment } \\
\text { number }\end{array}$ & Plot number & $\begin{array}{l}\text { No. of trees } \\
\text { per plot }\end{array}$ & $\begin{array}{l}\text { Density (no. of } \\
\text { trees per m2) }\end{array}$ & $\begin{array}{l}\text { Average tree } \\
\text { height }(\mathbf{m})\end{array}$ & $\begin{array}{l}\text { Tallest tree } \\
\text { height }(\mathrm{m})\end{array}$ & $\begin{array}{l}\text { Average tree } \\
\text { diameter }(\mathrm{cm})\end{array}$ & $\begin{array}{l}\text { Average top- } \\
\text { dying score }\end{array}$ \\
\hline 26 & 1 & 89 & 0.222 & 17.55 & 67.0 & 29.62 & 1.88 \\
\hline 26 & 2 & 71 & 0.177 & 8.80 & 25.0 & 30.37 & 1.85 \\
\hline 26 & 3 & 82 & 0.205 & 6.60 & 20.0 & 25.70 & 1.58 \\
\hline 28 & 1 & 67 & 0.167 & 8.28 & 40.0 & 40.01 & 2.51 \\
\hline 28 & 2 & 57 & 0.142 & 11.42 & 30.0 & 54.35 & 1.57 \\
\hline 28 & 3 & 77 & 0.195 & 8.50 & 25.5 & 39.48 & 1.45 \\
\hline 31 & 1 & 29 & 0.072 & 5.81 & 15.0 & 37.81 & 2.00 \\
\hline 31 & 2 & 40 & 0.100 & 6.64 & 11.5 & 28.85 & 1.78 \\
\hline 31 & 3 & 52 & 0.130 & 10.64 & 40.0 & 32.17 & 1.07 \\
\hline
\end{tabular}

The data in Table 3 show a noticeable (and highly significant: $\left.\sum \chi_{(2)}^{2}=40.29, \mathrm{p}<0.001\right)$ difference in the total number of individuals in the three compartments, with compartment 26 having most trees while compartment 31 had the fewest. The differences between plots within any one compartment were much less marked, though approaching significance $\left(\sum \chi_{(2)}^{2}=4.99, \mathrm{p}<0.10\right)$. However, there was no association between the plot and compartment variation when analysed by a $\chi^{2}$ contingency table $\left(\sum \chi_{(4)}^{2}\right.$ $=6.52, \mathrm{p}>0.10)$. Compartment 31 had a slightly greater number of species (between 3 and 5 per plot) compared to the others ( 2 or 3 species per plot). The changing number of individuals could be a reflection of the effects of top-dying, but could also be associated with features such as the accessibility of the three compartments and therefore the frequency of illicit felling of trees, or other factors. The lower number of individuals in compartment 31 might be allowing other species to enter because of reduced competition; again, however, an alternative interpretation might be that the extra species are less commonly targeted by felling operations which would allow a species such as Xylocarpus mekongensis to have a selective advantage over Heritiera fomes (Cheffy et. Al, 1985).

It may be observed that the average and tallest tree heights vary considerably from plot to plot (Table 2); this variation has meant that no consistent pattern is detectable so that the analyses of variance for these parameters are non-significant when comparing plots and compartments, although compartment 31 tends to have the lowest values. The average height values are consistent with the figure quoted by Iftekhar and Saenger (2008) that the canopy height seldom exceeds $10 \mathrm{~m}$, although clearly individual trees can be much taller than that. The average tree diameter data, when analysed by ANOVA, gave a nonsignificant plot effect but although not significant, the results for compartments were approaching significance $\left(\mathrm{F}_{\text {plot }}=0.59, \mathrm{df}=2, \mathrm{p}>0.10 ; \mathrm{F}\right.$ compartment $=5.46, \mathrm{df}=2$, $\mathrm{p}<0.10)$. The trees in compartment 28 tended to have a greater diameter than those of the other two compartments.

The plots had been originally selected from within each of the compartments to reflect an apparent increase in severity of top-dying, and the compartments had also been selected to reflect anticipated differences in this parameter. However, when the average top-dying intensity score was tested by a 2-factor Analysis of Variance, with Compartment as one factor and Plot as the other, the results proved not to be significant for either compartment or plot $\left(\mathrm{F}_{\text {compartment }}=0.49, \mathrm{df}=2, \mathrm{p}>0.10 ; \mathrm{F}_{\text {plot }}=5.36\right.$, df $=2$, $\mathrm{p}<0.10$ ), although the result for plots came close to significance. The fact that these results for top-dying did not prove to be significant, despite selection of the sites to reflect a gradient in the prevalence of top-dying, may be 
because of the limited range of score values that the topdying index could take. Also, further replicates of the number of plots would probably have helped make a significant result more likely. Besides this, since the three categories of top-dying intensity were chosen relative to each other within any one compartment, the absolute intensity might not have been exactly equivalent when comparing across different compartments. Nonetheless, the differences in intensity of top-dying are thought to be real, especially between plots, even if not proven statistically.

The data on various parameters of the sediments and water samples are given in Table 4 . The values for the moisture content are quite low, with an average of $21.4 \%$ but nowhere exceeding $30.2 \%$ by wet weight. This may be contrasted with the values thought necessary for mangroves of $47 \%$ minimum, usually much higher by Giglioli et al., (1966) ; (Faizuddin, 2003). The present results are less than half the expected (on average), suggesting that this will be adversely affecting the survivorship of the species in Sundarbans.

There was little variation in $\mathrm{pH}$ values, of soil or water, nor, apart from one anomalous result, for CEC of water. However, the CEC values for soil are lower for compartment 28 than for the other compartments. The $\mathrm{pH}$ values are consistent with values reported elsewhere of being neutral to slightly alkaline in both sediments (Matilal et al., 1986; Hoq et al., 2002; Haque et al., 2004; Islam et al., 2004; Gopal \& Chauhan, 2006; Biswas et al., 2009) and in water (Hoq et al., 2002; Islam et al., 2004; Wahid et al., 2007). Values of CEC between 12 and $34 \mathrm{Meq}_{100 \mathrm{~g}^{-1}}$ have been recorded previously (Matilal et al., 1986; IUCN, 1994; Iftekhar \& Islam, 2004); the present results show some values both below (compartment 28) and above (compartment 26) this reported range for the surface sediments.

Table 4. Results of various parameters of mangrove surface sediment and water samples taken from the selected plots. Values are means of sediment or water samples per plot.

\begin{tabular}{|c|c|c|c|c|c|c|c|}
\hline \multirow[b]{2}{*}{$\begin{array}{l}\text { Co } \\
\text { mp. } \\
\text { no. }\end{array}$} & \multicolumn{4}{|c|}{ Surface sediment } & \multicolumn{3}{|c|}{ Water } \\
\hline & $\begin{array}{l}\text { Plot } \\
\text { no. }\end{array}$ & $\begin{array}{l}\% \\
\text { М.C. }\end{array}$ & pH & $\begin{array}{l}\text { CEC } \\
\text { (Meq } \\
\text { 100g-1) }\end{array}$ & $\begin{array}{l}\text { Partic } \\
\text { le size } \\
(\mu)\end{array}$ & $\mathbf{p H}$ & $\begin{array}{l}\text { CEC } \\
(\mathrm{Meq} \\
\text { 100g-1) }\end{array}$ \\
\hline 26 & 1 & 23.91 & 7.54 & 36.4 & 12.69 & 7.11 & 19.5 \\
\hline 26 & 2 & 25.00 & 7.53 & 44.4 & 9.64 & 6.94 & 17.6 \\
\hline 26 & 3 & 30.24 & 7.61 & 10.3 & 11.67 & 7.27 & 18.8 \\
\hline 28 & 1 & 13.57 & 7.51 & 7.8 & 12.69 & 7.69 & 17.5 \\
\hline 28 & 2 & 20.40 & 7.71 & 3.9 & 11.67 & 7.47 & 18.2 \\
\hline 28 & 3 & 20.71 & 7.49 & 9.2 & 13.20 & 7.45 & 19.1 \\
\hline 31 & 1 & 13.85 & 7.42 & 31.6 & 11.67 & 7.27 & 17.3 \\
\hline 31 & 2 & 21.95 & 7.39 & 31.2 & 12.18 & 7.41 & 17.8 \\
\hline 31 & 3 & 23.91 & 7.52 & 25.6 & 11.67 & 7.22 & 17.4 \\
\hline
\end{tabular}

The results from the analyses of variance of soil parameters (Table 5) show many of the parameters tested to be markedly different in the different compartments but, except for soil $\mathrm{pH}$, not to vary significantly either between plots or in the interaction term. Soil $\mathrm{pH}$ was highly or very highly significant with both factors and the interaction.

Table 5. Analysis of Variance results, testing for the two factors of Compartment and Plot, together with their interaction, for the surface sediment nutrients and other parameters in the Sundarbans. Values given are the F-results together with probability levels. (Significances are indicated as follows: N.S. $=p>0.05 ; * *=p<0.01 ; * * *=p<0.001)$

\begin{tabular}{|c|c|c|c|}
\hline \multicolumn{4}{|c|}{ Include \%MC sediments, CEC sediments and particle size. Move $\mathrm{pH}$ near the top. Omit Fe. } \\
\hline Total Sodium $(\mathrm{Na})$ & $4.65, \mathrm{p}=0.014 * *$ & $2.14, p=0.13$ N.S. & $1.23, \mathrm{p}=0.31 \mathrm{~N} . \mathrm{S}$. \\
\hline Exchangeable $\mathrm{Na}$ & $3.47, \mathrm{p}=0.039 * *$ & $0.22, \mathrm{p}=0.80$ N.S. & $1.08, \mathrm{p}=0.38$ N.S. \\
\hline Soluble Na & $3.77, \mathrm{p}=0.031 * *$ & $2.20, \mathrm{p}=0.12 \mathrm{~N} . \mathrm{S}$. & $0.17, p=0.95$ N.S. \\
\hline Sediment $\mathrm{pH}$ & $11.67, \mathrm{p}<0.0005 * * *$ & $2.71, \mathrm{p}=0.07 * *$ & $7.46, \mathrm{p}<0.0005 * * *$ \\
\hline Sulphur (S) & $4.51, \mathrm{p}=0.016^{* *}$ & $0.32, \mathrm{p}=0.73$ N.S. & $1.86, \mathrm{p}=0.13 \mathrm{~N} . \mathrm{S}$. \\
\hline Calcium (Ca) & $0.37, p=0.69$ N.S. & $2.17, p=0.13$ N.S. & $1.60, p=0.19$ N.S. \\
\hline Soluble Potassium (K) & $1.67, p=0.20$, N.S. & $0.67, p=0.52$ N.S. & $1.64, p=0.18$ N.S. \\
\hline Exchangeable K & $5.15, \mathrm{p}=0.01 * *$ & $1.15, p=0.33$ N.S. & $0.80, p=0.53$ N.S. \\
\hline Total Nitrogen(N) & $0.63, p=0.54$ N.S. & $0.70, p=0.50$ N.S. & $1.02, p=0.40$ N.S. \\
\hline Iron $(\mathrm{Fe})$ & $0.38, p=0.69$ N.S. & $1.58, \mathrm{p}=0.22$ N.S. & $0.74, p=0.57$ N.S. \\
\hline
\end{tabular}

The fact that there is no significant difference between plots for any parameters (other than $\mathrm{pH}$ ) may be an indication that there is little variation in these parameters over the relatively small distances between plots; or the selection of plots based on top-dying has not selected for variation in these parameters because they are not linked to the amount of top-dying.

There were no significant variations in any of the parameters for the water samples, for compartments or for plots, although water $\mathrm{pH}$ was close to significance when comparing between plots. This presumably implies that the water characteristics were quite consistent between different locations. Given the significant differences in sediment results in Table 5, one might have expected water
$\mathrm{Na}$ concentrations to vary in a similar manner to sediment $\mathrm{Na}$ values, since most of the $\mathrm{Na}$ in the sediment has probably derived from that brought in by sea water. However, it is known that the salinity of the water in the Sundarbans varies substantially with season, being almost zero during the monsoon period (August - September), and increasing thereafter until about May (Hoq et al., 2002; Islam et al., 2004; Wahid et al., 2007); given the sampling period in the present study of October to March it is likely that much of the sampling was done at a time of low water salinity. It is interesting that there were no significant interactions (apart from soil $\mathrm{pH}$ ). This indicates that the effects evident between compartments can be considered independently of any plot effects, possibly operating at a 
broader geographical scale. Since soil $\mathrm{pH}$ showed significance in interaction as well as for the two factors separately, to demonstrate how the $\mathrm{pH}$ is varying across the two factors. In general, it would appear that the higher the $\mathrm{pH}$ value, the higher the amount of top-dying, although there is one result which does not fit with this trend. The pattern of variation between compartments is not consistent for the medium top-dying plots, but is consistent when comparing plots 1 and 3 in each compartment, compartment 31 having the highest pHs. Other results are incorporated as following: available N 55.9-154ppm; P 1621ppm; K 542.1-1844.2ppm in soils (Matilal et al., 1986). $\mathrm{N}$ values higher in east, but $\mathrm{P}$ varied over small distances (K too?) - no obvious reasons. A high nutrient content (esp. $\mathrm{K}$ and $\mathrm{S}$ ), helpful for mangrove species (Biswas et al., 2009). Na 5.7-29.8 meq 100g-1; Cl 5.7-23.2 meq 100g-1 (Iftekhar \& Islam, 2004). From Islam et al 2004: total $\mathrm{N}$ in sediment: $0.12-0.15 \%$; P: $4.92-8.40 \mu \mathrm{g} / \mathrm{g}$; S: 114.71-290.05 $\mu \mathrm{g} / \mathrm{g}$; Ca: $15.50-19.00 \mathrm{me} / 100 \mathrm{~g}$; Mg: 3.50-5.50 me/100g; K: 0.53-0.93me/100g; Cu: 4.69-8.04 $\mu \mathrm{g} / \mathrm{g} ; \mathrm{Fe}: 22.20-59.20$ $\mu \mathrm{g} / \mathrm{g}$; Mn: 23.92-45.52 $\mu \mathrm{g} / \mathrm{g}$; Zn: 0.26-1.50 $\mu \mathrm{g} / \mathrm{g}$

From Hoq et al 2002: total N: 0.11-0.13 g/100g; P: 2.61$11.3 \mu \mathrm{g} / \mathrm{l}$ high in post monsoon period; $\mathrm{K}$ : $0.1-0.3$ meq/100g; Ca: 15 meq/100g; Mg: 3.6-6 meq/100g; $\mathrm{Na}$ in sediments high in pre-monsoon and dry winter seasons: $0.38-1.71 \mathrm{meq} / 100 \mathrm{~g}$

The variation in heavy metals across the compartments and plots has been reported in a previous paper (Awal et al., 2009). Results of a two-factor ANOVA showed that the elements bismuth, scandium, strontium and vanadium varied significantly across the three compartments.

\subsection{The Relationship between Tree Growth and Characteristics of Surface Sediments and Water}

The strength of relationship between the tree growth parameters and the sediment and water characteristics was tested using product-moment correlation coefficients. None of the sediment or water parameters tested showed a significant relationship with tree height (Table 6), with exchangeable $\mathrm{Na}$ being the only element that even came close $(p<0.10)$. Therefore, it does not appear that tree height is substantially affected by the parameters tested. It should be noted that illicit felling of trees does occur in the areas studied, and it is possible that this extra factor might be influencing these results by leading to selective removal of the largest trees, making it more difficult for any correlation to be established. Similar results may be demonstrated when comparing the same parameters with tree diameter (Table 6). In this case, however, not only exchangeable $\mathrm{Na}$ but also $\mathrm{Pb}$ gave results close to significance, while exchangeable $\mathrm{K}$ did reach the threshold of significance at the $5 \%$ level. The result for $\mathrm{Na}$ was positive, while those for $\mathrm{Pb}$ and $\mathrm{K}$ were negative (inverse) relationships. The negative correlation for $\mathrm{K}$ indicates that an increase in the amount of $\mathrm{K}$ is associated with a decrease in the girth of trees. This is an unexpected result, as it might be expected that providing extra nutrients to the trees should lead to them growing better. It is unclear what might be leading to the relationship actually observed. The trend of greater $\mathrm{Pb}$ leading to reduced growth in the girth of trees is a more predictable response of the plants to heavy metal presence, but does not reach the threshold for significance.

Table 6. Pearson's correlation coefficient values from assessing the relationship between tree height $(\mathrm{m})$ or tree diameter $(\mathrm{cm})$ and the concentrations of various elements (in ppb) or other chemical parameters. All results (with 7 degrees of freedom) were not significant $(p>0.05)$ except where marked $*(0.05>p>0.01)$. Those results labelled $<0.1$ were not significant, but were close to being so.

\begin{tabular}{lllll}
\hline $\begin{array}{l}\text { Soil parameter / } \\
\text { element }\end{array}$ & $\begin{array}{l}\text { Correlation with tree } \\
\text { height } \\
\text { r-value }\end{array}$ & Probability & $\begin{array}{l}\text { Correlation with tree } \\
\text { diameter } \\
\text { r-value }\end{array}$ & Probability \\
\hline Soil EC & 0.171 & 0.661 & & \\
Soil pH & 0.181 & 0.642 & 0.452 & 0.221 \\
Water pH & -0.280 & 0.466 & 0.540 & 0.133 \\
Lead $(\mathrm{Pb})$ & 0.392 & 0.297 & -0.655 & $0.056<0.1$ \\
Nickel $(\mathrm{Ni})$ & -0.438 & 0.238 & -0.017 & 0.965 \\
Exchangeable K & 0.576 & 0.105 & -0.672 & $0.047^{*}$ \\
Exchangeable Na & 0.617 & $0.077<0.1$ & -0.656 & $0.055<0.1$ \\
Soluble Na & -0.012 & 0.976 & -0.264 & 0.492 \\
Soil Sulphur & 0.233 & 0.547 & -0.466 & 0.206 \\
Tin (Sn) & 0.086 & 0.826 & -0.258 & 0.502 \\
Zinc $(\mathrm{Zn})$ & 0.219 & 0.571 & -0.232 & 0.548 \\
\hline
\end{tabular}

\subsection{The Relationship between the Amount of top-Dying and Other Parameters}

Correlations between the average top-dying index and parameters of tree growth were calculated using the Spearman's Rank correlation coefficient. A summary of the outcome for these analyses is given in Table 7. None of the growth parameters were significantly related to amount of top-dying.

Table 7. Comparison by Spearman's Rank Correlation Coefficient of the relationship between intensity of top-dying and various parameters of tree structure and growth. All probability values were non-significant.

\begin{tabular}{lll}
\hline Parameter & r-value (7 df) & Probability \\
\hline Tree height $(\mathrm{m})$ & -0.113 & 0.773 \\
Tallest tree height $(\mathrm{m})$ & 0.072 & 0.854 \\
Tree diameter $(\mathrm{cm})$ & 0.067 & 0.865 \\
Tree density $($ per $\mathrm{m} 2)$ & 0.021 & 0.956 \\
\hline
\end{tabular}

Correlations between the average top-dying index and parameters of the sediment and water from Table 4 were also calculated using the Spearman's Rank correlation coefficient. None of the parameters were significantly related to amount of top-dying. A correlation of the percentage sediment moisture content with the average topdying index, however, showed a significant relationship $\left(\mathrm{r}_{\mathrm{s}}\right.$ $=-0.736,7 \mathrm{df}, \mathrm{p}=0.024)$. The results on other soil and water parameters, are shown in Table 3.29. Summarise only, since all N.S. Also need results for sediment $\mathrm{pH}$, water $\mathrm{pH}, \mathrm{Ex} \mathrm{K}$, $\mathrm{Na}$, other $\mathrm{Na}$ and $\mathrm{S}$.

The various element concentrations arising from the analysis by ICP-MS were tested for relationship to the 
amount of top-dying using Spearman's rank correlation coefficient. There were no elements which gave a significant correlation with the index of top-dying, although $\mathrm{Sn}$ gave a (negative) correlation $\left(\mathrm{r}_{\mathrm{s}}=-0.610,7 \mathrm{df}\right.$; $\mathrm{t}$-value $\left.=-2.037\right)$ which was close to significance $(\mathrm{p}<0.1)$, and the result for $\mathrm{Pb}$ was fairly close to significance $\left(\mathrm{r}_{\mathrm{s}}=0.51, \mathrm{p}<0.2\right)$. It is clear that, within the scope of the present samples and data collected, there is no indication that heavy metal concentrations are influencing the amount of top-dying.

The statistical result indicated for $\mathrm{Sn}$ is an inverse trend, that is, the more $\mathrm{Sn}$ is present, the less top-dying there is. If it is presumed that this is a real result (if not quite significant) and is not simply an artefact from the statistical analyses, the implication is that either Sn directly inhibits top-dying, or that it is negatively correlated indirectly because of another factor that is linked directly with top-dying. Mangrove forests generally require a very specific physico-chemical environment to flourish, and changes in one element may have effects on the general balance of that environment and affect other elements which could influence top-dying, even if the specific element is not having a direct effect on it. Unlike the results for $\mathrm{Sn}$, the result for $\mathrm{Pb}$ is a positive one, greater $\mathrm{Pb}$ concentration being related to more top-dying. This trend is perhaps easier to suggest an interpretation for: the increased presence of the metal weakens the trees, and allows them to be more affected by the agents of top-dying such as the pathogens.

\section{Conclusions}

Bangladesh is a land of many wonders. With a reach history, diversified culture and impeccable natural beauty within land of virgin lush green and ancient civilization. In trying to assess which factors might be responsible for the problem of top-dying, particularly of Heritiera fomes trees, in the Sundarbans, Bangladesh, the present work has placed particular emphasis on analysing surface sediment and water samples from the study sites to determine the concentrations of various chemical elements, so that the relationships between these chemical constituents and the severity of topdying could be explored. The relationships between the growth and regeneration of the trees and the concentrations of these chemical parameters have also been assessed. Although certain trace elements have previously been shown to be present in concentrations that could be considered elevated (see Awal et al., 2009), none of them proved to be significantly correlated with the amount of top-dying, or to vary in concentrations in a manner consistent with the plots' perceived top-dying status (as assessed by ANOVA). One factor which should be taken into account, when considering these results is the potential for considerable variation in elemental concentrations, both spatially and temporally. Awal et al. (2009) have demonstrated significant differences in the concentrations of some elements over the different compartments studied in Bangladesh, while Sarika and Chandramohanakumar (2008) have also found significant spatial variation in heavy metal concentrations in mangrove sediments in India. Although these latter authors did not find any temporal variation in their sediment samples, Sarkar et al (2007) found heavy metal values to be higher in the late monsoon period (September - October), as did Haque et al. (2004) for most of the metals they studied; Hoq et al. (2002) found heavy metal concentrations in the mangrove litter to vary with the season (more in the winter); and Sarkar et al. (2003) found considerable seasonal variation in metals in water samples, also associated with the timing of the monsoon rains. Therefore, the lack of significant correlations or patterns of variation associated with top-dying status reported here would need to be confirmed by further studies over a broader spatial scale and at different times of the year. A second factor to take into account with regard to the present results is that there may not be a strong correlation between the concentrations of metals in the sediments and the concentrations in the plants themselves (e.g. Thomas \& Fernandez, 1997). Thus the effect of metals on top-dying might be related to tissue concentrations in the plants rather than to sediment concentrations. Clearly, studies of this potential relationship need to be carried out. Thus, the general hypothesis that greater top-dying is directly related to elevated heavy metal contamination is not supported by the present results, although generally raised concentrations may well act as a stressor which could contribute to reduction in the health of the trees and surrounding people. Although there were only a few individual chemical elements which showed significant correlations with the amount of top-dying, there was evidence of elevated heavy-metal concentrations of many elements in the Sundarbans, which are likely to contribute to the increase in top-dying observed. There were also significant differences between different areas in the Sundarbans, and evidence of water supply problems to the system. Therefore, it is concluded that several factors such as heavy metal concentrations are responsible for this increase in top-dying, rather than one specific heavy metal concentration only.

\section{Acknowledgements}

The work of MAA was supported financially by the Peoples' Republic of Bangladesh and the Asian Development Bank (ADB), whom we thank. Particular thanks are due to the ADB head office, Manila for their support and help. I thank sincerely Dr. W.G.H. Hale (Principal Supervisor), University of Bradford, UK, Professor Mike Ashmore (Technical Supervisor), University of York, UK and Dr. P.J. Hogarth for their advice and comments on the work; Dr. Ben Stern and the staff at the Analytical Centre, Bradford, for their help with the ICPMS analyses; Professor Sirajul Hoque, and staff at Dhaka University for providing facilities; and staff of the Forestry Service, Bangladesh Government, for field assistance. Moreover I indebted to Munshi Aowlad Hossain, Mrs. Ashrafunness, Dr. Shanaj Khatun, Munshi Tasneem Redowan, Marwa Ashra, Munshi Abul Kalam Azad, Abdus Salam and family members for their inspiration and help. 


\section{References}

[1] Allen, S.E., Grimshaw, H.M., Parkinson, J.A. \& Quarmby, C. (1974) Chemical analysis of ecological materials. Blackwell Scientific Publications, Oxford. (cited in Hoq et al., 2002)

[2] Awal, M.A. (2007). Analysis of possible environmental factors causing top-dying in mangrove forest trees in the Sundarbans in Bangladesh. $\mathrm{PhD}$ thesis, University of Bradford.

[3] Awal, M.A., Hale, W.H.G. \& Stern, B. (2009). Trace element concentrations in mangrove sediments in the Sundarbans, Bangladesh. Marine Pollution Bulletin, 58(12), 1944-1948.

[4] Biswas et al (2007)

[5] Black et al (1965) Methods of soil analysis (part 1): physical and mineralogical properties, including statistics of measurement and sampling, pp. 562-566. American Society of Agronomy Inc., Madison, Wisconsin, USA.

[6] Blasco, F., Saenger, P. \& Janodet, E. (1996) Mangroves as indicators of coastal change. Catena, 27, 167-178.

[7] Chaffey, D.R., Millar, F.R. \& Sandom, J.H. (1985). A forest inventory of the Sundarbans, Bangladesh, Main Report. Project Report No. 140, 196pp, Overseas Development Agency, London, U.K., pp. 195-196.

[8] Davis, J. \& Freitas, F. (1970). Physical and chemical methods of soil and water analysis. Soils Bulletin 10. FAO, Rome. (cited in Ellison et al 2000)

[9] Dyer, K.R. (1986). Coastal and estuarine sediment dynamics. John Wiley \& Sons, Chichester.

[10] Ellison, A.M., Mukherjee, B.B. \& Karim, A. (2000) Testing patterns of zonation in mangroves: scale dependence and environmental correlates in the Sundarbans of Bangladesh. Journal of Ecology, 88, 813-824.

[11] Gibson, I.A.S. (1975). Report on a visit to the People's Republic of Bangladesh, 28 February to 1 April 1975. Unpublished Report, Overseas Development Agency, London, 28pp.

[12] Gopal, B. \& Chauhan, M. (2006) Biodiversity and its conservation in the Sundarban mangrove ecosystem. Aquatic Sciences, 68(3), 338-354.

[13] Haque, M.R., Ahmad, J.U., Chowdhury, M.D.A., Ahmed, M.K. \& Rahman, M.S. (2004) Seasonal variation of heavy metals concentration in sediments of the rivers and estuaries of Sundarban mangrove forest. Asian Journal of Microbiology, Biotechnology and Environmental Sciences, 6(2), 175-185.

[14] Hartung, F., Werner, R., Hoque, M.I., Alam, Sk.S., Khan, S., Paul, A.R. \& Mühlbach, H.-P. (1998) Association of phytopathogenic bacteria with top-dying disease of Sundri tree (Heritiera fomes) in Bangladesh. Angewandte Botanik, $72,48-55$

[15] Hoq, M.E., Islam, M.L., Paul, H.K., Ahmed, S.U. \& Islam, M.N. (2002). Decomposition and seasonal changes in nutrient constituents in mangrove litter of Sundarbans mangrove, Bangladesh. Indian Journal of Marine Sciences,

\section{$31,130-135$.}

[16] Hossain, M.S. (2001). Biological aspects of the coastal and marine environment of Bangladesh. Ocean \& Coastal Management, 44, 261-282.

[17] Iftekhar, M.S. \& Saenger, P. (2008) Vegetation dynamics in the Bangladesh Sundarbans mangroves: a review of forest inventories. Wetlands Ecology \& Management, 16, 291-312.

[18] Islam, M.L., Alam, M.J., Rheman, S., Ahmed, S.U. \& Mazid, M.A. (2004). Water quality, nutrient dynamics and sediment profile in shrimp farms of the Sundarbans mangrove forest, Bangladesh. Indian Journal of Marine Sciences, 33, 170-176.

[19] Karim (1994) in IUCN report pp. 43-74.

[20] Mitra, A., Chakraborty, R. \& Banerjee, K. (2008) Monthly variation of $\mathrm{Zn}, \mathrm{Cu}$ and $\mathrm{Pb}$ in and around Indian Sundarbans. Proceedings of the National Academy of Sciences of India Section B - Biological Sciences, 78, 234-245.

[21] Matilal, S., Mukherjee, B.B., Chaterjee, N. \& Gupta, M.D. (1986) Studies on soil and vegetation of mangrove forest of Sundarbans. Indian Journal of Marine Sciences, 15, 181-184

[22] Momen, A.K.A.2014; Mamun-or-Rashid,2014. 'Bangladesh marching Towards Progress' by Permanent Mission of Bangladesh to the United Nations, 26th March, 2014.

[23] Mukhopadhyay, S.K., Biswas, H., De, T.K. \& Jana, T.K. (2006) Fluxes of nutrients from the tropical River Hooghly at the land-ocean boundary of Sundarbans, NE coast of Bay of Bengal, India. Journal of Marine Systems, 62, 9-21.

[24] Peters, R.L. \& Darling, J.D. (1985). The greenhouse effect and nature reserves. Biological Science, 35, 707-717. (Get a copy for me from the library / online if possible).

[25] Phillips and somebody (1994). Which one is it from the thesis list? Get Phillips \& Gentry 94 from the library: Science 263, 954-958. Then see which one it is!

[26] Prain, D. (1903). Flora of the Sundarban. Records of the Botanical Survey of India. Periodical Expert Book Agency, Delhi, pp. 231-370

[27] Sarika, P.R. \& Chandramohanakumar, N. (2008). Distribution of heavy metals in mangrove sediments of Cochin estuary. Research Journal of Chemistry and Environment, 12, 37-44.

[28] Sarkar, S.K., Bhattacharya, A. \& Bhattacharya, B. (2003) The river Ganga of northern India: an appraisal of its geomorphic and ecological changes. Water Science and Technology, 48, 121-128.

[29] Siddiqi, N.A., Islam, M.R., Khan, M.A.S. \& Shahidullah, M. (1993). Mangrove nurseries in Bangladesh. Mangrove ecosystems occasional papers, International Society for Mangrove Ecosystems, Japan, pp. 1-14.

[30] Snedaker, S. (1991) Notes on the Sundarbans with emphasis on geology, hydrology and forestry. In: Seidensticker, J., Kurin, R. \& Townsend, A.K. (eds). The commons in south Asia: societal pressure and environmental intensity in the Sundarbans. http://www.smartoffice.com/Tiger/Proceedings.html (in Iftekhar \& Islam 2004) Try to get online.

[31] Sokal, R.R. \& Rohlf, F.J. (1981). Biometry. Freeman, New York. 
[32] Tam, N.F.Y., Li, S.H., Lan, C.Y., Chen, G.Z., Li, M.S. \& Wong, Y.S. (1995) Nutrients and heavy-metal contamination of plants and sediments in Futian mangrove forest. Hydrobiologia, 295, 149-158. (Recheck if worth including)

[33] Thomas, G. \& Fernandez, T.V. (1997) Incidence of heavy metals in the mangrove flora and sediments in Kerala, India. Hydrobiologia, 352, 77-87.

[34] UN-ESCAP (1987). Final Report: Volume 2. Coastal environment management plan for Bangladesh, Bangkok, Thailand.

[35] UN-ESCAP (1988). Coastal environment management plan for Bangladesh. Bangkok, Thailand, pp. 7-34.
[36] Vane, C.H., Harrison, I., Kim, A.W., Moss-Hayes, V. \& Vickers, B.P. (2009) Organic and metal contamination in surface mangrove sediments of South China. Marine Pollution Bulletin, 58, 134-144.

[37] Wahid, S.M., Babel, M.S. \& Bhuiyan, A.R. (2007) Hydrologic monitoring and analysis in the Sundarbans mangrove ecosystem, Bangladesh. Journal of Hydrology, $332,381-395$.

[38] Zar, J.H. (1984). Biostatistical Analysis (2nd ed.). PrenticeHall International, London. (is there a 3rd ed? Ref in MacFarlane et al 2007 is for 1999). 